\title{
Active Anion Delivery by Self-Propelled Micro-
}

\section{swimmers}

Seyyed Mohsen Beladi-Mousavi, ${ }^{1,2}$ Jonas Klein, ${ }^{2}$ Bahareh Khezri, ${ }^{1}$ Lorenz Walder ${ }^{2}$ and Martin Pumera ${ }^{1,3,4,5 *}$

${ }^{1}$ Center for the Advanced Functional Nanorobots, Department of Inorganic Chemistry, University of Chemistry and Technology, Technická 5, Prague, Czech Republic

${ }^{2}$ Institute of Chemistry of New Materials, Center of Physics and Chemistry of New Materials, University of Osnabrück, Barbarastr. 7, Osnabrück D-49069, Germany

3 Department of Chemical and Biomolecular Engineering, Yonsei University, 50 Yonsei-ro, Seodaemun-gu, Seoul 03722, Korea

4 Department of Medical Research, China Medical University Hospital, China Medical University, No. 91 Hsueh-Shih Road, Taichung, Taiwan

5 Future Energy and Innovation Laboratory, Central European Institute of Technology, Brno University of Technology, Purkyňova656/123, Brno, CZ-616 00, Czech Republic

*Author for correspondence. E-mail: pumera.research@gmail.com 


\section{Table of content:}

1. Fabrication of PV/Ni/Pt microswimmers - Figure S1

2. Potential dependence electrodeposition of PV (Amperometry)

Figure S2

3. Synthesis of PV - Figure S3 - Figure S4

4. Characterization of the electrodeposited PV (ATR - Raman - TGA)

Figure S5

5. Elemental analysis of PV/Ni/Pt microswimmers (SEM / EDS)

Figure S6

6. Propulsion of microswimmers - Figure S7 - Equation S1

7. Cycling stability of PV (CV) - Figure S8

8. Weight change during reduction / oxidation of $\mathrm{PV}(\mathrm{CV}-\mathrm{eQCM})$

Figure S9

9. Ultrafast reduction/oxidation of PV (Amperometry) - Figure S10

10. Adsorption efficiency of organic molecules (UV-Vis) - Figure S11

11. Coverage efficiency calculations - Equation S2 - Equation S3

12. Schematic illustration of the electrochemical release mechanism

Figure S12

13. Anion re-adsorption in the presence of oxygen (eQCM) - Figure S13

Video Tracking of PV/Ni/Pt microswimmer in presence of $0.5 \% \mathrm{v} / \mathrm{v} \mathrm{H}_{2} \mathrm{O}_{2}(0.5 \%$ S1. w/v SDS).

Video Tracking of PV/Ni/Pt microswimmer in presence of $1 \% \mathrm{v} / \mathrm{v} \mathrm{H}_{2} \mathrm{O}_{2}(0.5 \% \mathrm{w} / \mathrm{v}$ S2. SDS).

Video Tracking of PV/Ni/Pt microswimmer in presence of $2 \% \mathrm{v} / \mathrm{v} \mathrm{H}_{2} \mathrm{O}_{2}(0.5 \% \mathrm{w} / \mathrm{v}$ S3. SDS).

Video Tracking of PV/Ni/Pt microswimmer in presence of $3 \% \mathrm{v} / \mathrm{v} \mathrm{H}_{2} \mathrm{O}_{2}(0.5 \% \mathrm{w} / \mathrm{v}$ S4. SDS).

Video Tracking of PV/Ni/Pt microswimmer in presence of $5 \% \mathrm{v} / \mathrm{v} \mathrm{H} 2 \mathrm{O} 2(0.5 \%$ S5. w/v SDS). 


\section{Fabrication of PV/Ni/Pt microswimmers}

a
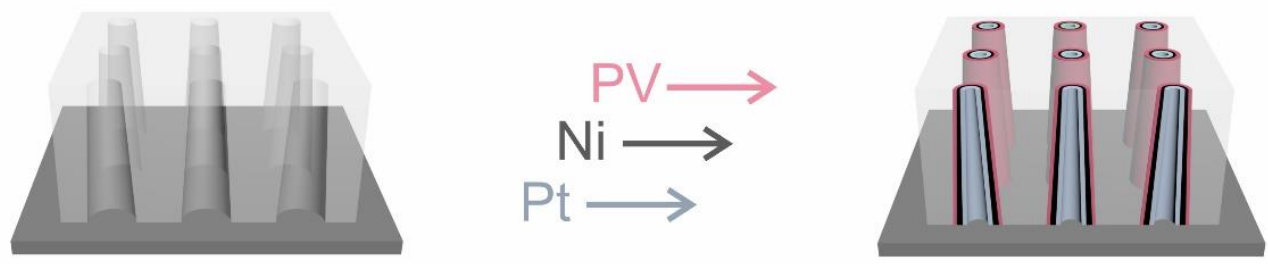

b
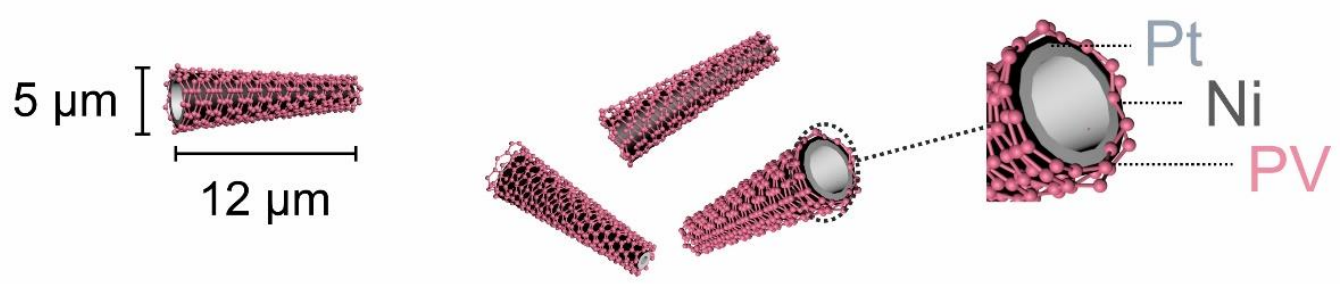

C

d
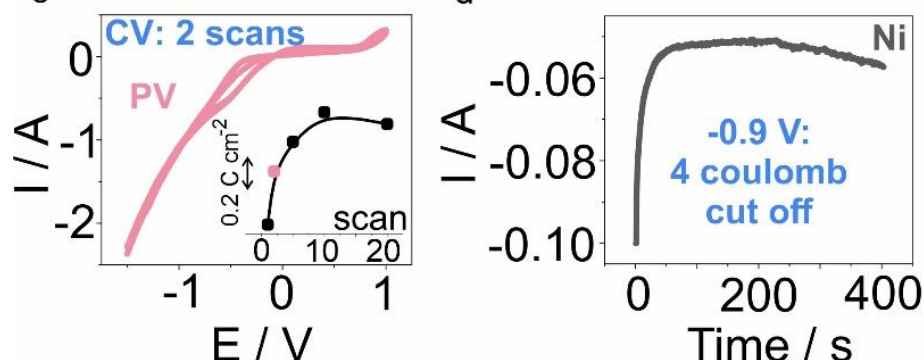

e

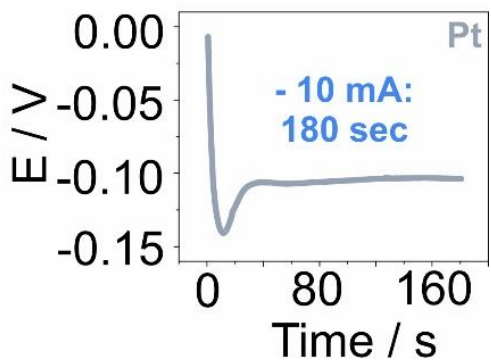

Figure S1. Template-assisted fabrication of microswimmers. a) Electrodeposition of PV, Ni, and $\mathrm{Pt}$ inside pores of a PC membrane (one side is copper), followed by (b) dissolution of the membrane in dichloromethane (DCM) and release of microswimmers. c) electrodeposition of $\mathrm{PV}$ via $2 \mathrm{CV}$ cycles ( $+1 \mathrm{~V}$ to $-1.5 \mathrm{~V}$; vs $\mathrm{Ag} / \mathrm{AgCl})$; inset: charge of deposited $\mathrm{PV}$ on a glassy carbon (GC) film after 20 cycles. d) Electrodeposition of Ni using an amperometric method ($0.9 \mathrm{~V}-4$ coulomb charge cut off). e) Electrodeposition of $\mathrm{Pt}$ via a potentiometric method (-10 A for $180 \mathrm{sec})$.

Three layered $\mathrm{PV} / \mathrm{Ni} / \mathrm{Pt}$ microswimmers were prepared through electrodeposition of each component inside the pores of a membrane (Figure S1a, b). PV with an average length of 15 subunits was prepared based on the Zincke reaction (Figure S3, S4). ${ }^{1}$ The polymer layer was electrodeposited via $2 \mathrm{CV}$ cycles of the as-prepared PV (Figure S1c) at a scan rate of 50 $\mathrm{mV} \mathrm{S}^{-1}$ and cut off potentials of $1 \mathrm{~V}$ and $-1.5 \mathrm{~V}(v s \mathrm{Ag} / \mathrm{AgCl})$. This process is based on the precipitation of polymers at negative potentials (Figure S2), where polymers have no charge 
and are therefore insoluble in aqueous media (see properties of electrodeposited PV in Figure S5). The higher electrical conductivity of $\mathrm{PV}$ in radical cation $\left(\mathrm{PV}^{\bullet+}\right)$ and neutral $\left(\mathrm{PV}^{0}\right)$ states ${ }^{2}$ provide an appropriate substrate for electrodeposition of the following layer i.e., $\mathrm{Ni}$. The magnetic Ni layer was deposited via an amperometric method applying $-0.9 \mathrm{~V}$ with cut off charge of 4 coulombs (Figure S1d), and the Pt layer was deposited using a galvanostatic method via applying $-10 \mathrm{~V}$ for $180 \mathrm{sec}$ (Figure S1e). The synthesized microswimmers were released by dissolving the membrane in dichloromethane (DCM) (Figure 1c). The PV layer has a porous structure - observed by scanning electron microscopy (SEM) - which provide high surface area for anion adsorption (Figure 1d). The successful synthesis of all 3 layers including PV (carbon), Ni and Pt were confirmed by energy-dispersive X-ray spectroscopy (EDX) (Figure S6). 


\section{Potential dependence electrodeposition of PV (Amperometry)}

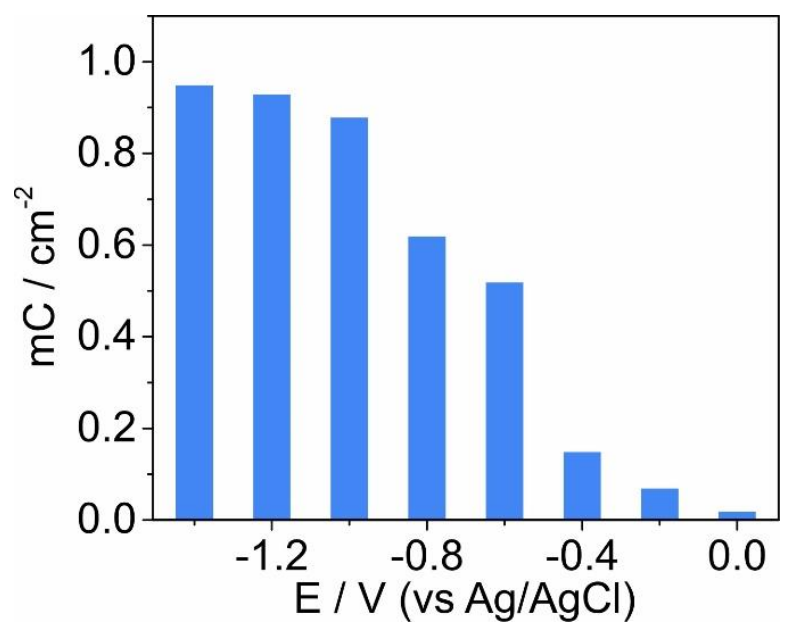

Figure S2. Electrodeposition of PV on the surface of glassy carbon (GC) at different potentials.

Electrodeposition of PV via amperometry measurements at different potentials is evaluated on the surface of a flat working electrode (WE) i.e., GC. The successful deposition of $\mathrm{PV}$ is qualified via $\mathrm{CV}$ tests (potential range: $0.3 \mathrm{~V}-(-1 \mathrm{~V})$; vs $\mathrm{Ag} / \mathrm{AgCl}$ ), through the calculation of discharge capacity. The collected charges at potentials higher than $-0.4 \mathrm{~V}$ have increased significantly, however it becomes almost constant at after $-1 \mathrm{~V}$. This is attributed to complete charge neutralization of $\mathrm{PV}$ at potentials higher than $-0.8 \mathrm{~V}\left(\mathrm{PV}^{++}+2 \mathrm{e}^{-} \rightarrow \mathrm{PV}^{0}\right)$ (Figure 2a) and therefore, precipitation of the neutral polymers from the aqueous solution. Notably, $\mathrm{PV}$ in radical cation state $\left(\mathrm{PV}^{\circ+}\right)$ is still soluble in aqueous solution, which is confirmed by low deposition at potentials lower than $-0.4 \mathrm{~V}$. 


\section{Synthesis of PV}

This polymer was prepared based on the Zincke reaction. 1,1'-Bis-(2,4-dinitrophenyl)4,4'-bipyridinium dichloride as one starting material was prepared based on previous reports. ${ }^{1}$
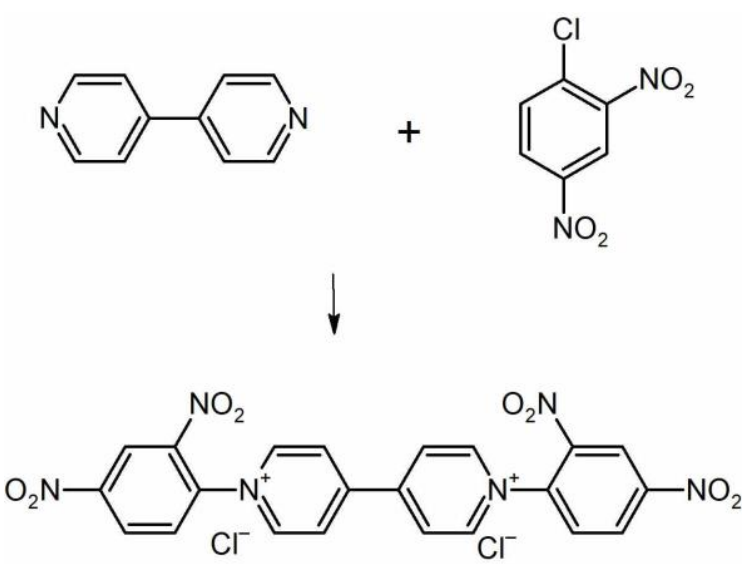

Figure S3. Synthesis of 1,1'-Bis-(2,4-dinitrophenyl)-4,4'-bipyridinium dichloride.

1,1'-Bis-(2,4-dinitrophenyl)-4,4'-bipyridinium dichloride. This bipyridinium salt was prepared based on a previous method by Beladi-Mousavi et al. 2, 4-dinitrochlorobenzene (14.0 g, $70 \mathrm{mmol})$ and 4, 4'-bipyridine (3.2 g, $20 \mathrm{mmol})$ were individually dissolved in acetonitrile and then mixed and refluxed (72 hours). A yellow powder precipitated, which was filtered and washed several times with acetonitrile and acetone. The TLC in MeOH: HOAc: $\mathrm{H}_{2} \mathrm{O} ; 10 / 4 / 1$ and ${ }^{1} \mathrm{H}$ NMR confirmed a pure product (yield: $\left.74 \%\right) .{ }^{1} \mathrm{H}$ NMR $\left(\mathrm{D}_{2} \mathrm{O}, 250 \mathrm{MHz}\right)$ $\delta: 9.41(\mathrm{~d}, \mathrm{~J}=7.5 \mathrm{~Hz}, 4 \mathrm{H}) ; 9.34(\mathrm{~d}, \mathrm{~J}=2.5 \mathrm{~Hz}, 2 \mathrm{H}) ; 8.89(\mathrm{~d}, \mathrm{~J}=4 \mathrm{~Hz}, 4 \mathrm{H}) ; 8.87(\mathrm{~d}, \mathrm{~J}=5 \mathrm{~Hz}$, $2 \mathrm{H}) ; 8.25(\mathrm{~d}, \mathrm{~J}=10 \mathrm{~Hz}, 2 \mathrm{H})$. 

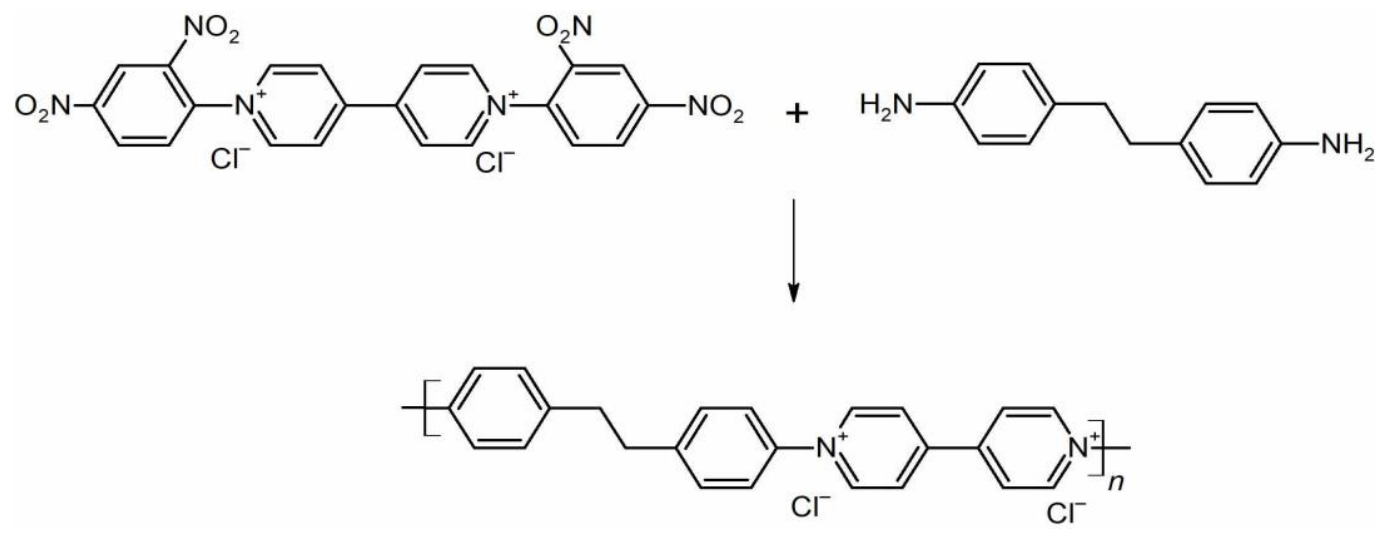

Figure S4. Synthesis of PV.

Polyviologen. $0.8 \mathrm{mmol}$ of $4,4^{\prime}-$ ethylenedianiline $(0.17 \mathrm{~g})$ and bis-[1,1'-(2,4dinitrophenyl-4,4'-bipyridinium dichloride)] (0.45 g) were individually dissolved in $\mathrm{MeOH} / \mathrm{H}_{2} \mathrm{O}$ (8/2), then mixed and refluxed for 14 days. Afterwards, the solvent was evaporated, and the dark yellow powder was dispersed in acetone and refluxed for $12 \mathrm{~h}$. The dispersion was filtered, and the obtained powder was washed several times with acetone and dried under high vacuum for 24 hours (94\% yield). The obtained polymer has an average chain length of 15 subunits. This was calculated from ${ }^{1} \mathrm{H}$ NMR (250 MHz; $\left.\mathrm{CD}_{3} \mathrm{OD}\right)$ of fraction 2 (A) $\delta: 9.57(4 \mathrm{H}) ; 8.96(4 \mathrm{H}) ; 8.89(\mathrm{~d}, \mathrm{~J}=4 \mathrm{~Hz}, 4 \mathrm{H}) ; 7.9(4 \mathrm{H}) ; 7.75(4 \mathrm{H}) ; 3.23(4 \mathrm{H})$. 


\section{Characterization of the electrodeposited PV (ATR - Raman - TGA)}
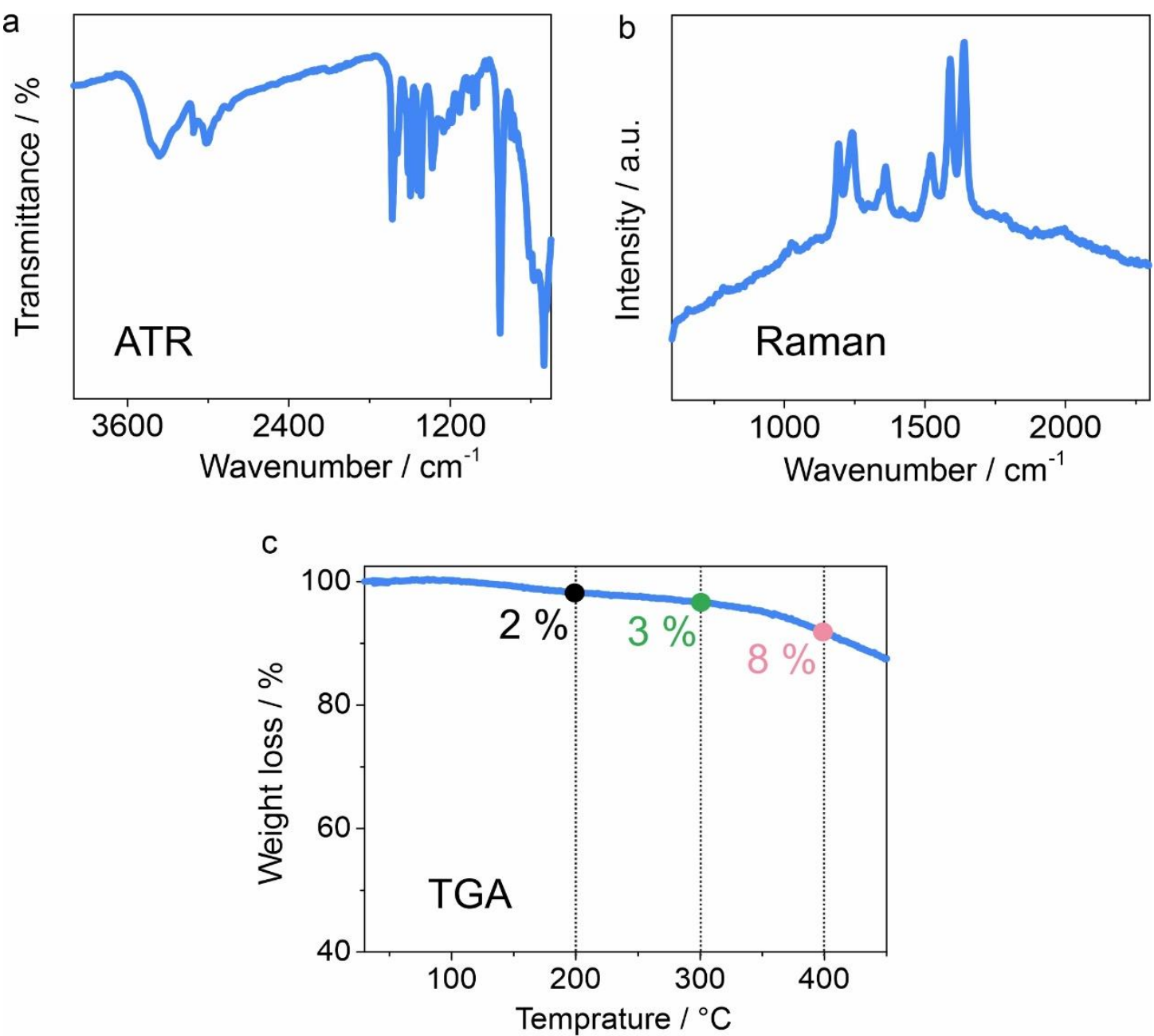

Figure S5. Characterization of the electrodeposited PV.

The electrodeposited PV film was characterized via different methods including attenuated total reflection infrared spectroscopy (ATR-IR), Raman spectroscopy and thermal gravimetric analysis (TGA).

The ATR-IR spectrum of PV is demonstrated in Figure S5a, exhibiting various molecular vibrations originated from functional groups of the polymer. ${ }^{1,3}$ The peak at 3034 $\mathrm{cm}^{-1}$ is assigned to the stretching of the $\mathrm{C}-\mathrm{H}$ of the aromatic rings, while the peak at $1495 \mathrm{~cm}^{-1}$ is assigned to the vibrational stretching of $\mathrm{C}=\mathrm{C}$ and $\mathrm{C}=\mathrm{N}$ of bipyridine rings. Peaks located at 
$1495 \mathrm{~cm}^{-1}$ and $1252 \mathrm{~cm}^{-1}$ correspond to stretching of $\mathrm{C}-\mathrm{H}$ and $\mathrm{C}-\mathrm{N}$ groups, respectively. The in-plane and out of plane deformation of the $-\mathrm{CH} 2$ groups appear at $1294 \mathrm{~cm}^{-1}$ and $833 \mathrm{~cm}^{-1}$, respectively.

The Raman spectrum of PV shows characteristic peaks of phenylic viologen molecules (Figure S5b). ${ }^{4-5}$ The inner-ring vibration of viologen appeares at $1640 \mathrm{~cm}^{-1}$, while the peaks at $1360 \mathrm{~cm}^{-1}$ and $1589 \mathrm{~cm}^{-1}$ are assigned to the stretching vibrations of the $\mathrm{C}-\mathrm{C}$ in benzene rings. The peak at $1521 \mathrm{~cm}^{-1}$ is assigned to the in-plane vibration of $\mathrm{C}-\mathrm{H}$ bending. Finally, the stretching vibration of $\mathrm{C}-\mathrm{N}$ of the first carbon in the phenyl ring and the inter-ring vibration of C-C appear at $1194 \mathrm{~cm}^{-1}$ and $1242 \mathrm{~cm}^{-1}$, respectively.

TGA of PV is analyzed to study the stability of this organic polymer at different temperatures, which is important regarding the real-world application of PV based microswimmers. The thermogram of PV is shown in Figure $5 \mathrm{Sc} .2 \%, 5 \%$, and $8 \%$ capacity losses are observed at $200^{\circ} \mathrm{C}, 300^{\circ} \mathrm{C}$ and $400^{\circ} \mathrm{c}$, respectively, demonstrating thermal stability of PV. 


\section{Elemental analysis of PV/Ni/Pt microswimmers (SEM/ EDS)}
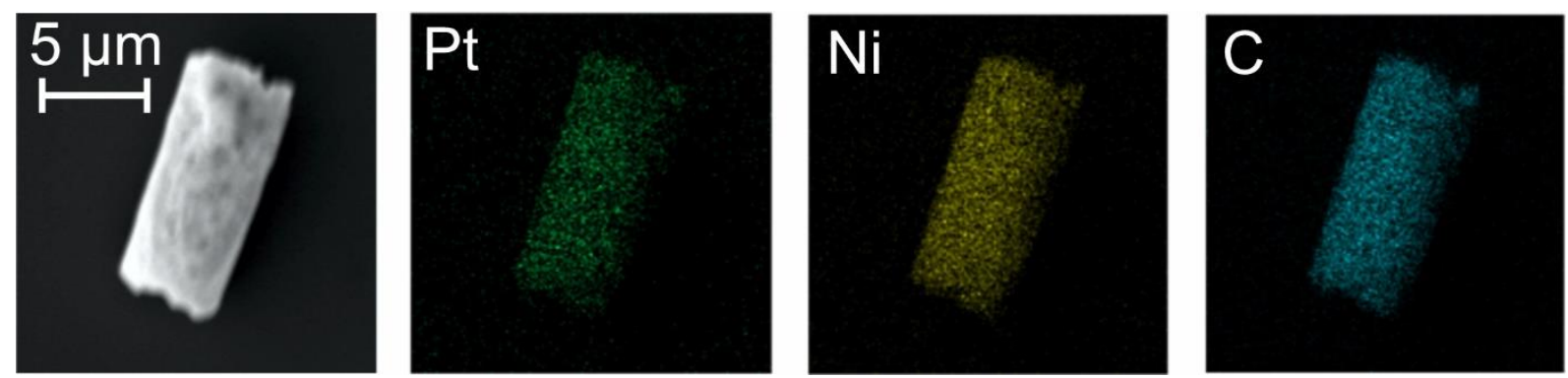

Figure S6. Scanning Electron Microscopy / Energy Dispersive X-Ray Spectroscopy (SEM/EDS) of PV/Ni/Pt microswimmers.

EDS analysis confirms the homogeneous distribution of $\mathrm{Pt}, \mathrm{Ni}$, and $\mathrm{C}$ in the tubular structure of microswimmer. 


\section{Propulsion of microswimmers}

a

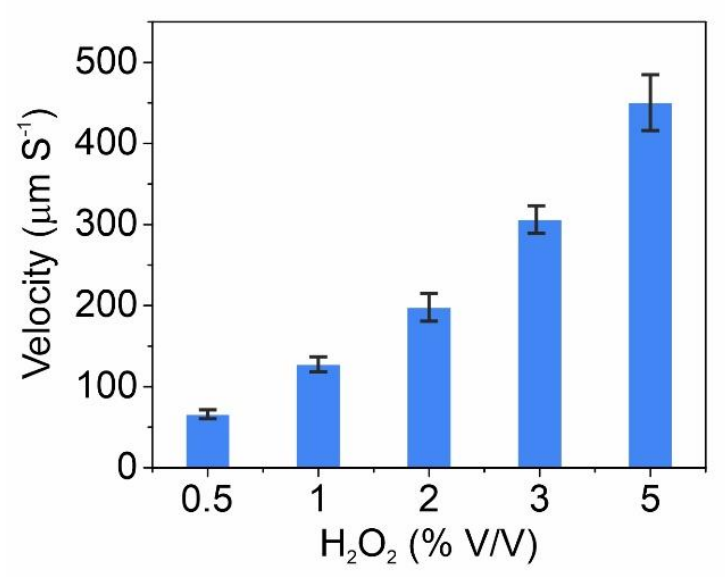

C

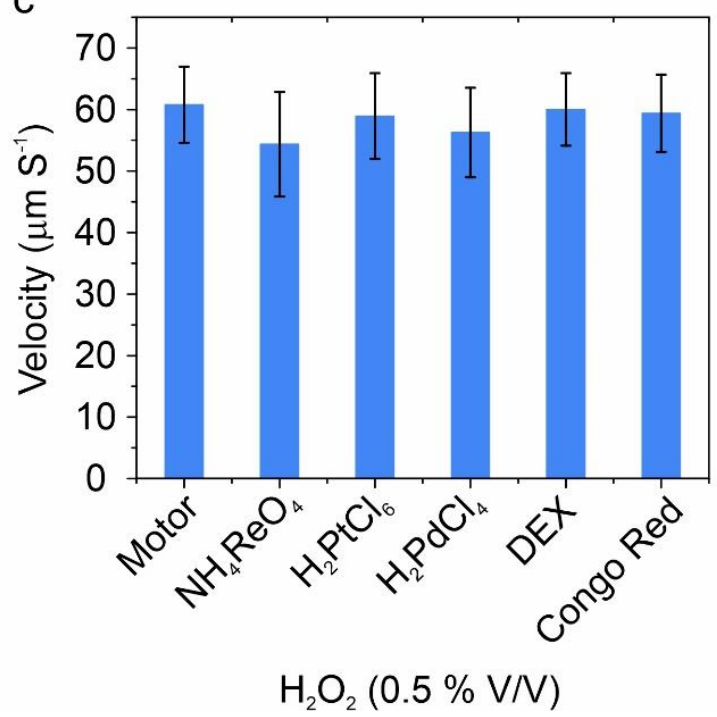

b

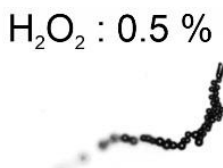

$2 \%$

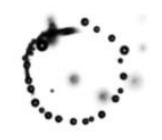

$3 \%$

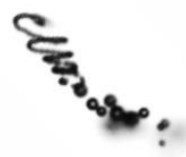

$\stackrel{30 \mu \mathrm{m}}{\longmapsto}$

Figure S7. Propulsion of PV/Ni/Pt microswimmers. a) Impact of $\mathrm{H}_{2} \mathrm{O}_{2}$ concentrations on the velocity of microswimmers; the reported velocities are an average of 30 motion experiments; Error bars demonstrate the standard deviation for the velocity at each fuel concentration. b) Propulsion of microswimmers in the presence of a different concentration of $\mathrm{H}_{2} \mathrm{O}_{2}$. All measurements are in the presence of $0.5 \% \mathrm{w} / \mathrm{v}$ sodium dodecyl sulfate (SDS); see video S1VideoS5. c) Propulsion of microswimmers in the presence of different ions.

A propulsion of the microswimmers was studied at different concentrations of fuel $\left(\mathrm{H}_{2} \mathrm{O}_{2}\right)$ (Figure $\mathrm{S} 7 \mathrm{a}$ ). The microswimmers were tracked via the oxygen bubble tail produced as a result of decomposition of $\mathrm{H}_{2} \mathrm{O}_{2}$ at the Pt side (Figure $\mathrm{S} 7 \mathrm{~b}$ ). As expected, the swimmers have higher velocity and more complex motion at higher concentrations of the fuel i.e., from $66 \mu \mathrm{m} \mathrm{s}^{-1}$ in $0.5 \% \mathrm{H}_{2} \mathrm{O}_{2}$ until $450 \mu \mathrm{m} \mathrm{s}^{-1}$ in $5 \% \mathrm{H}_{2} \mathrm{O}_{2}$. 
The speed of the microswimmers motion is influenced by the driving and dragging forces. The Stokes's law can be used to predict the drag force of the swimmers of different sizes and shapes. The morphology and shape of the microswimmers are affecting the drag force, while the influence of the shape can be corrected by applying a correction factor to the Stokes's law.

The drag force $(25.6 \mathrm{pN})$ of a microswimmer was calculated using the Equation $\mathrm{S} 1$ introduced by $\mathrm{Li}$ et al. for tubular microswimmers in low Reynolds number according to Stokes' law in hydrodynamics.

$F=\frac{2 \pi \mu L \vartheta}{\ln (L / r)-0.5}$ Equation S1

where $\mathrm{F}$ represents the drag force, $\mu$ is the dynamic viscosity, $\mathrm{L}, \vartheta$ and $\mathrm{r}$ are the length, velocity and maximum radius (cross-section) of the microswimmer. The propulsion force (which acts in the opposite direction of drag force) of PV microswimmer is adequate as it is shown in Figure S7.

Figure S7c demonstrates the velocity of microswimmers in the presence of different salt. It is observed that the velocity in $0.5 \% \mathrm{H}_{2} \mathrm{O}_{2}$ is almost independent from the presence of additional of salts. 


\section{Cycling stability of PV (CV)}

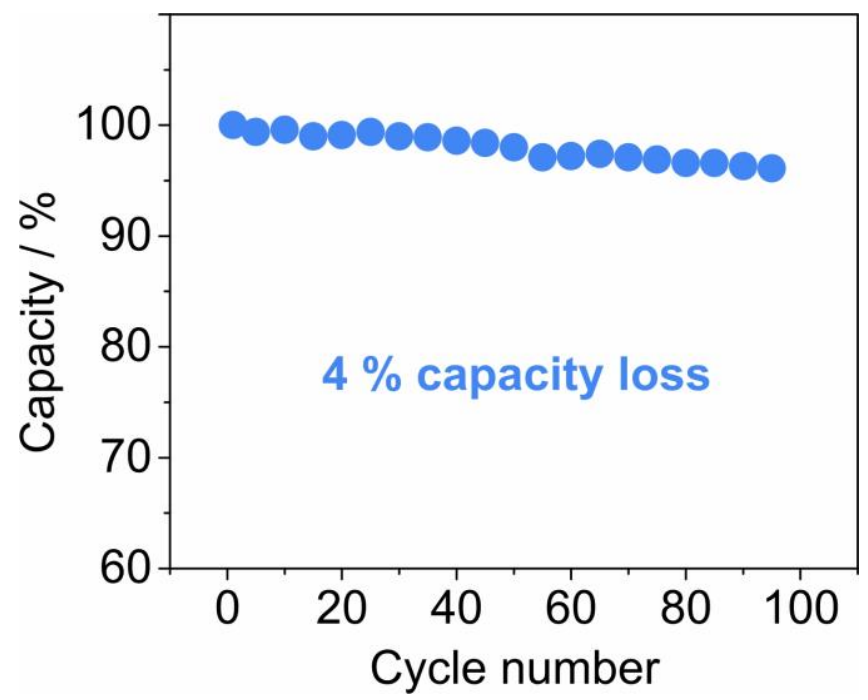

Figure S8. Cycling stability of PV in aqueous electrolyte.

Stability of PV electrodeposited on $\mathrm{GC}\left(\Gamma_{\mathrm{PV}}=2.3 \times 10^{-7} \mathrm{~mol} \mathrm{~cm}^{-2}\right)$ measured via $\mathrm{CV}$ in $0.1 \mathrm{M} \mathrm{KCl}$ aqueous electrolyte and potential range of $0.3 \mathrm{~V}$ to $-0.8 \mathrm{~V}$. The capacity loss after 100 cycles were only $4 \%$. 


\section{Weight change during reduction / oxidation of PV (CV - eQCM)}

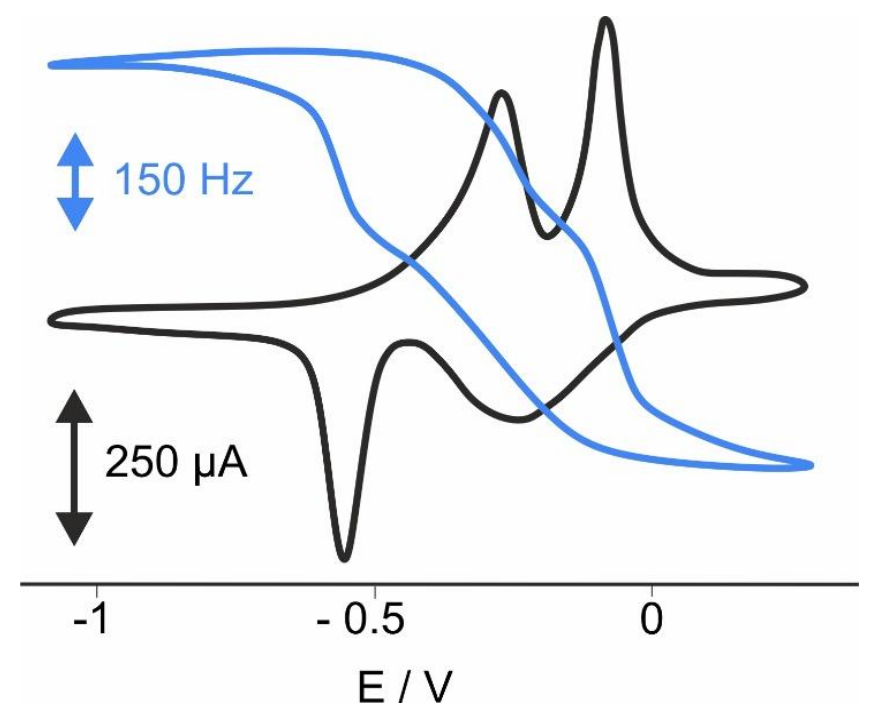

Figure S9. eQCM frequency response of PV $\left(4.3 \times 10^{-8} \mathrm{~mol}\right.$ subunits $\left.\mathrm{cm}^{-2}\right)$ for one $\mathrm{CV}$ scan. Electrolyte: $0.1 \mathrm{M}$ aqueous $\mathrm{KCl}$; Reference electrode: $\mathrm{Ag} / \mathrm{AgCl}$; counter electrode: $\mathrm{Pt}$ wire; scan rate: $50 \mathrm{mV} \mathrm{s}^{-1}$.

During the reduction and the oxidation of PV, 4 peaks at the CV scan were observed that are corresponding to the two steps reduction $\left(\mathrm{PV}^{++} \rightarrow \mathrm{PV}^{\bullet+} \rightarrow \mathrm{PV}^{0}\right)$ and two steps oxidation of $\mathrm{PV}\left(\mathrm{PV}^{0} \rightarrow \mathrm{PV}^{\bullet+} \rightarrow \mathrm{PV}^{++}\right)$(black). Each change of the redox state of $\mathrm{PV}$ corresponds to a change in the frequency $(\mathrm{Hz})$ (blue), which demonstrate a removal and an insertion of $\mathrm{Cl}^{-}$during the reduction and the oxidation, respectively. 
9. Ultrafast reduction/oxidation of PV (Amperometry)

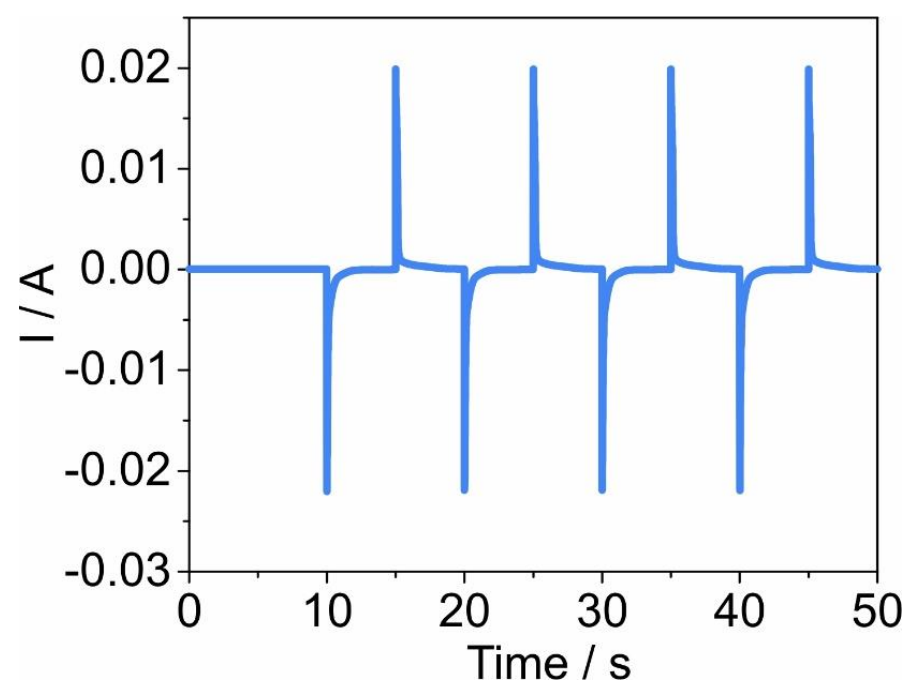

Figure S10. Amperometry analysis of $10 \mu \mathrm{g} \mathrm{cm}^{-2} \mathrm{PV}$ during 4 redox cycles. Cut off potential: $0.3 \mathrm{~V}$ and -1.1. $\mathrm{V}$; electrolyte: $0.1 \mathrm{M}$ aqueous $\mathrm{KCl}$; Reference electrode: $\mathrm{Ag} / \mathrm{AgCl}$; counter electrode: Pt wire; scan rate: $50 \mathrm{mV} \mathrm{s}^{-1}$. 


\section{Adsorption efficiency of organic molecules (UV-Vis)}
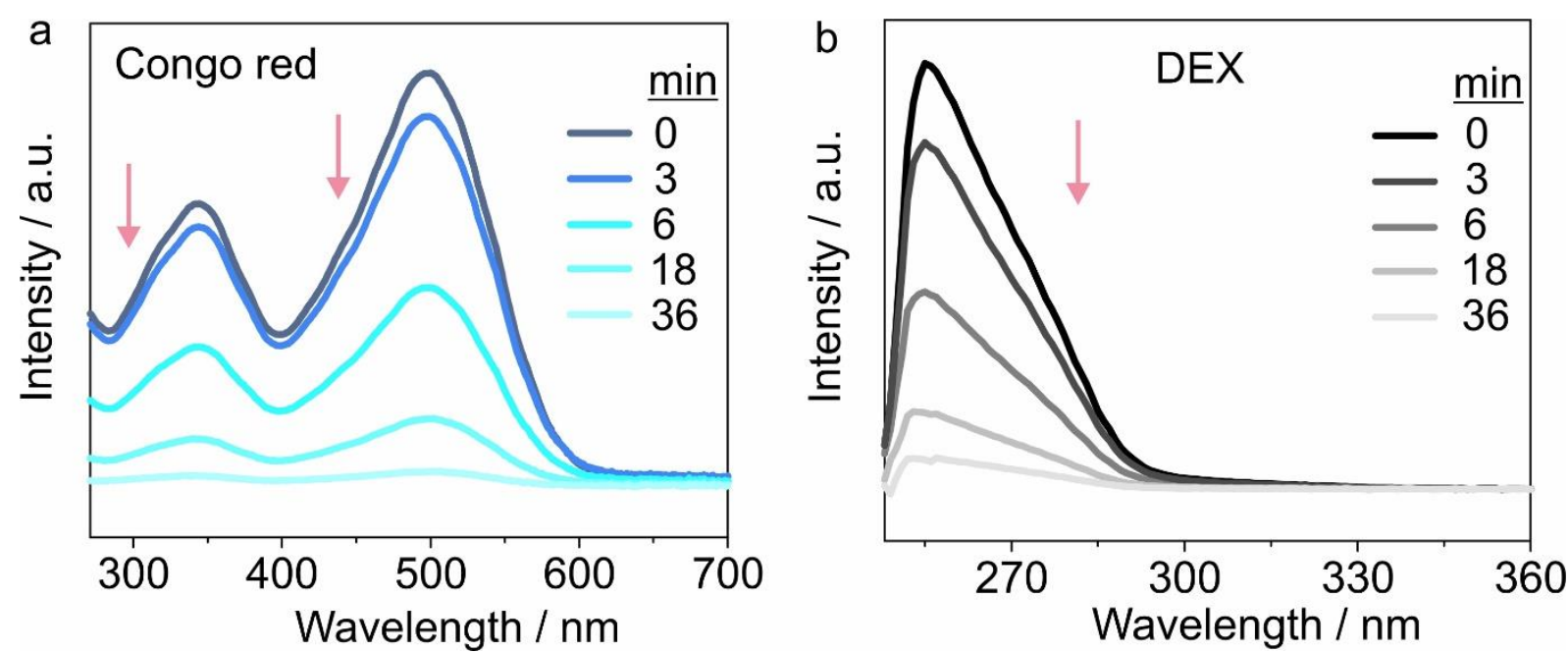

Figure S11. Collection of organic anions. The UV-Vis spectrum of congo red (a) and DEX (b) solutions before addition of microswimmers $(0 \mathrm{~min})$ and in the presence of $\mathrm{PV}^{++}\left(2 \mathrm{Cl}^{-}\right.$ )/Ni/Pt microswimmers after 3, 6, 18 and $36 \mathrm{~min}$. The absorption intensity decreases in the presence of the self-propelled microswimmers $\left(1 \%(\mathrm{v} / \mathrm{v}) \mathrm{H}_{2} \mathrm{O}_{2}\right.$ and $0.5 \%(\mathrm{w} / \mathrm{v})$ SDS). 


\section{Coverage efficiency calculations}

Theoretical capacity of PV layer:

The calculation is based on the surface area of the microswimmer, charge density of the PV, the quantity of the anionic species collected by microswimmers and the number of the microswimmers involved in the anion collection tests.

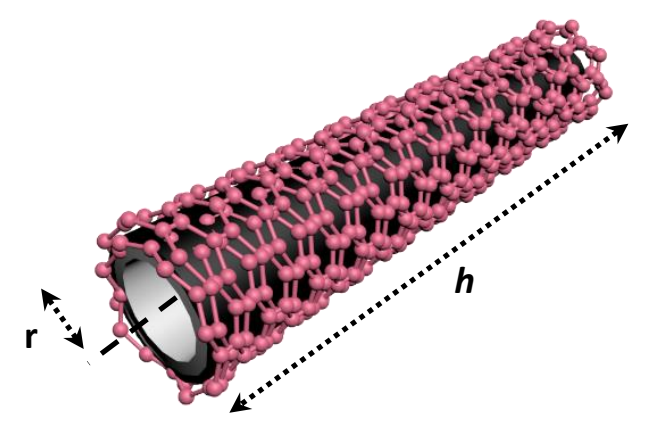

The surface area of the cone shape tube $\left(A_{\text {tube }}\right)$ has been calculated using the fallowing equation:

$A_{\text {tube }}=\pi r\left(r+\sqrt{\left(h^{2}+r^{2}\right)}\right.$

(Equation

S2)

where $\mathrm{r}$ represents the radius of the tube and $\mathrm{h}$ is the length.

$1 \mu \mathrm{m}$ thick PV film has $145 \mathrm{mC} \mathrm{cm}{ }^{-2}$ charge, which translates to $1.5 \times 10^{-6} \mathrm{~mol} \mathrm{~cm}^{-2}$ of stored anions. Considering the dimension of the microswimmers $(5 \mu \mathrm{m} \times 12 \mu \mathrm{m})$ and the thickness of the PV outer layer (average: $150 \mathrm{~nm}$ ), $2.55 \times 10^{-13}$ mol can theoretically be stored in each microswimmer:

Microswimmer area:

$A_{\text {tube }}=\pi r\left(r+\sqrt{\left(h^{2}+r^{2}\right)}=\pi \times 2.5 \times\left(2.5+\sqrt{\left(12^{2}+2.5^{2}\right)}\right)=115.9 \mu m^{2}\right.$

$A=1.159 \times 10^{-10} \mathrm{~m}^{2}$ 
Charge density per microswimmer:

$1 \mu \mathrm{m}$ thickness of PV: $145 \mathrm{mC} \mathrm{cm}{ }^{-2}$

Since each $96500 \mathrm{C} / \mathrm{mol} \rightarrow 145 \mathrm{mC} \mathrm{cm}{ }^{-2}=1.5 \times 10^{-6} \mathrm{~mol} \mathrm{~cm}^{-2}$ (for $1 \mu \mathrm{m}$ thickness of PV)

Per microswimmer:

\begin{tabular}{|l|c|}
\hline $1 \mathrm{~cm}^{2}$ & $=1.5 \times 10^{-6} \mathrm{~mol}$ \\
\hline $\mathrm{A}_{\text {microswimmer }}=1.159 \times 10^{-6} \mathrm{~cm}^{2}$ & $\mathrm{X}=1.159 \times 10^{-6} \times 1.5 \times 10^{-6}=1.7 \times 10^{-12} \mathrm{~mol}$ \\
\hline
\end{tabular}

\begin{tabular}{|l|c|}
\hline $1 \mu \mathrm{m}$ & $1.7 \times 10^{-12} \mathrm{~mol}$ \\
\hline $0.15 \mu \mathrm{m}$ & $\mathrm{X}=0.15 \times 1.7 \times 10^{-12}$ \\
& $=2.55 \times 10^{-13} \mathrm{~mol}$ \\
\hline
\end{tabular}

Number of microswimmers needed to remove targeted anions:

The ppm values are only for the metallic moieties.

\section{$\underline{\mathrm{NH}}_{4} \underline{\mathrm{ReO}}_{4}$}

$6 \mathrm{ppm}=3.2 \times 10^{-2} \mathrm{mM}\left(\right.$ initial concentration $\left.\left(\mathrm{C}_{0}\right)\right)$

In $4 \mathrm{ml}$ of test solution: $1.3 \times 10^{-4} \mathrm{mmol}=1.3 \times 10^{-7} \mathrm{~mol}$

\begin{tabular}{|l|l|l|}
\hline Efficiency & $100 \%$ & $50 \%$ \\
\hline Req. swimmer & $=\frac{1.3 \times 10^{-7}}{2.55 \times 10^{-13}}$ & $=\frac{6.5 \times 10^{-8}}{2.55 \times 10^{-13}}$ \\
& $=5.1 \times 10^{5}$ & $=2.5 \times 10^{5}$ \\
\hline
\end{tabular}

$\underline{\mathrm{H}}_{2} \underline{\mathrm{PtCl}_{6}}:$

$6 \mathrm{ppm}=0.077 \mathrm{mM}$ (It's our initial concentration $\left(\mathrm{C}_{0}\right)$ ) 
In $4 \mathrm{ml}$ of test solution: $3.1 \times 10^{-4} \mathrm{mmol}=3.1 \times 10^{-7} \mathrm{~mol}$

\begin{tabular}{|l|l|l|}
\hline Efficiency & $100 \%$ & $98 \%$ \\
\hline Req. swimmer & $=\frac{3.1 \times 10^{-7}}{2.55 \times 10^{-13}}$ & $=\frac{3.0 \times 10^{-7}}{2.55 \times 10^{-13}}$ \\
& $=1.2 \times 10^{6}$ & $=1.2 \times 10^{6}$ \\
\hline
\end{tabular}

\section{$\underline{\mathrm{H}}_{2} \mathrm{PdCl}_{2}:$}

$6 \mathrm{ppm}=0.13 \mathrm{mM}$ (It's our initial concentration $\left(\mathrm{C}_{0}\right)$ )

In $4 \mathrm{ml}$ of test solution: $5.2 \times 10^{-4} \mathrm{mmol}=5.2 \times 10^{-7} \mathrm{~mol}$

\begin{tabular}{|l|l|l|}
\hline Efficiency & $100 \%$ & $96 \%$ \\
\hline Req. swimmer & $=\frac{5.2 \times 10^{-7}}{2.55 \times 10^{-13}}$ & $=\frac{5.0 \times 10^{-7}}{2.55 \times 10^{-13}}$ \\
& $=2 \times 10^{6}$ & $=2 \times 10^{6}$ \\
\hline
\end{tabular}

Dex:

$0.1 \mathrm{mM}$ (It's our initial concentration $\left(\mathrm{C}_{0}\right)$ )

In $4 \mathrm{ml}$ of test solution: $4.0 \times 10^{-4} \mathrm{mmol}=4.0 \times 10^{-7} \mathrm{~mol}$

\begin{tabular}{|l|l|l|}
\hline Efficiency & $100 \%$ & $92 \%$ \\
\hline Req. swimmer & $=\frac{4.0 \times 10^{-7}}{2.55 \times 10^{-13}}$ & $=\frac{3.7 \times 10^{-7}}{2.55 \times 10^{-13}}$ \\
& $=1.6 \times 10^{6}$ & $=1.5 \times 10^{6}$ \\
\hline
\end{tabular}

Congo Red:

$0.1 \mathrm{mM}$ (It's our initial concentration $\left(\mathrm{C}_{0}\right)$ ) 
In $4 \mathrm{ml}$ of test solution: $4.0 \times 10^{-4} \mathrm{mmol}=4.0 \times 10^{-7} \mathrm{~mol}$

\begin{tabular}{|l|l|l|}
\hline Efficiency & $100 \%$ & $96 \%$ \\
\hline Req. swimmer & $=\frac{4.0 \times 10^{-7}}{2.55 \times 10^{-13}}$ & $=\frac{3.8 \times 10^{-7}}{2.55 \times 10^{-13}}$ \\
& $=1.6 \times 10^{6}$ & $=1.5 \times 10^{6}$ \\
\hline
\end{tabular}

Efficiency:

Number of microswimmers used in each experiment $=2.6 \times 10^{6}$

Efficiency $=\frac{\text { Number of microswimmers needed }}{\text { Number of microswimmers used in each experiment }} \times 100$

\section{$\underline{\mathrm{NH}}_{4} \underline{\operatorname{ReO}} 4$}

$\left(2.5 \times 10^{5} / 2.6 \times 10^{6}\right) \times 100=9.6 \%$

\section{$\underline{\mathrm{H}_{2}} \underline{\mathrm{PtCl}_{6}}$}

$\left(1.2 \times 10^{6} / 2.6 \times 10^{6}\right) \times 100=46.2 \%$

\section{$\underline{\mathrm{H}}_{2} \underline{\mathrm{PdCl}}_{4}$}

$\left(2 \times 10^{6} / 2.6 \times 10^{6}\right) \times 100=86.9 \%$

\section{$\underline{\text { Dex }}$}

$\left(1.5 \times 10^{6} / 2.6 \times 10^{6}\right) \times 100=57.7 \%$

\section{Congo red}

$\left(1.5 \times 10^{6} / 2.6 \times 10^{6}\right) \times 100=57.7 \%$ 


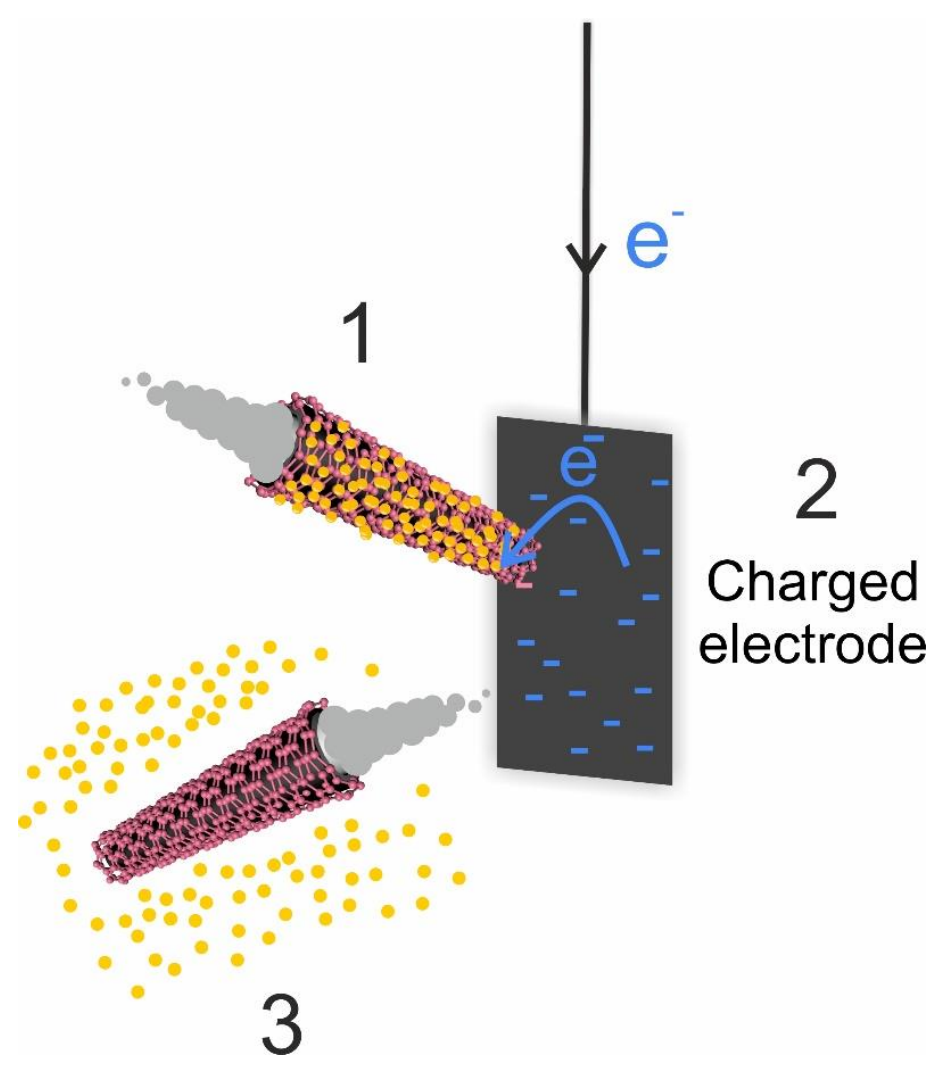

Figure S12. Schematic illustration on the electrochemical release of anions from $\mathrm{PV} / \mathrm{Ni} / \mathrm{Pt}$ microswimmers. 


\section{Anion re-adsorption in the presence of oxygen (eQCM)}
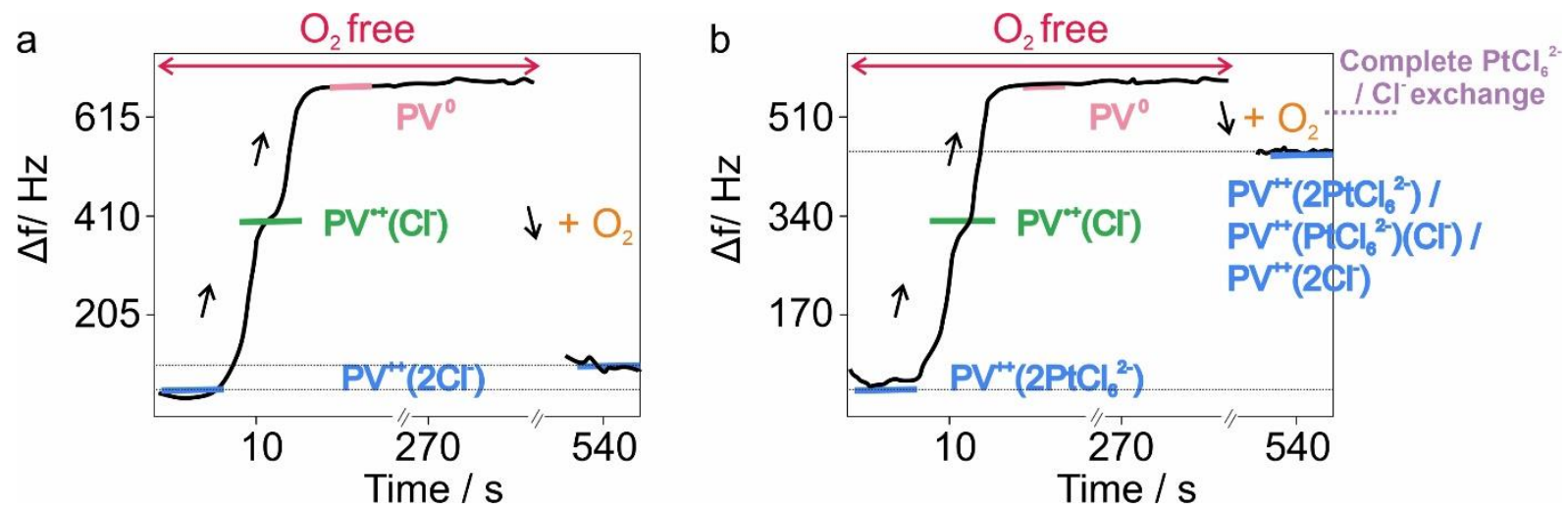

Figure S13. eQCM analyses demonstrating re-adsorption of anions by electrochemically reduced $\mathrm{PV}\left(\mathrm{PV}^{0}\right)$ in the presence of oxygen. Electrochemical reduction of $\mathrm{PV}^{++}\left(2 \mathrm{Cl}^{-}\right)$and $\mathrm{PV}^{++}\left(2 \mathrm{PtCl}_{6}^{2-}\right)$ (b) $(\mathrm{CV}$, see Figure $2 \mathrm{C})$ in $0.1 \mathrm{mM} \mathrm{KCl}$ solution in an oxygen-free environment, followed by oxygen saturation. Electrochemical setup: $\mathrm{RE}: \mathrm{Ag} / \mathrm{AgCl} ; \mathrm{CE}: \mathrm{Pt}$ wire; v: $50 \mathrm{mV} \mathrm{s}^{-1}$.

Thin PV films are deposited onto a quartz crystal and reduced via scanning the potential from $0.3 \mathrm{~V}$ to $-0.9 \mathrm{~V}$, which transfers $\mathrm{PV}^{++}\left(2 \mathrm{Cl}^{-}\right)$to $\mathrm{PV}^{\bullet+}\left(\mathrm{Cl}^{-}\right)$and subsequently to $\mathrm{PV}^{0}$. The reduced PV has an almost constant frequency, however, the addition of oxygen to the aqueous media caused a frequency decrease - close to the initial value -, which is attributed to the oxidation of $\mathrm{PV}^{0}$ and re-adsorption of $\mathrm{Cl}^{-}$from solution. A similar measurement was performed on a thin film of $\mathrm{PV}^{++}\left(2 \mathrm{PtCl}_{6}{ }^{2-}\right)$. A reduction of the polymer caused a release of $\mathrm{PtCl}_{6}{ }^{2-}$ ions, however, its oxidation in the presence of oxygen in a 0.01 $\mathrm{mM} \mathrm{KCl}$ solution mostly results in adsorption of $\mathrm{Cl}^{-}\left(\mathrm{PV}^{++}\left(2 \mathrm{Cl}^{-}\right)\right)$, in addition to much smaller amount of $\mathrm{PtCl}_{6}{ }^{2-}$ re-adsorption $\left(\mathrm{PV}^{++}\left(2 \mathrm{PtCl}_{6}{ }^{2-}\right)\right)$ and $\left.\mathrm{PV}^{++}\left(\mathrm{PtCl}_{6}{ }^{2-}\right)\left(\mathrm{Cl}^{-}\right)\right)$. 


\section{REFRENCES}

1. Beladi-Mousavi, S. M.; Sadaf, S.; Mahmood, A. M.; Walder, L., High Performance Poly(viologen)-Graphene Nanocomposite Battery Materials with Puff Paste Architecture. ACS Nano 2017, 11, 8730-8740.

2. Porter, W. W.; Vaid, T. P., Isolation and Characterization of Phenyl Viologen as a Radical Cation and Neutral Molecule. J. Org. Chem. 2005, 70, 5028-5035.

3. Gadgil, B.; Damlin, P.; Ääritalo, T.; Kankare, J.; Kvarnström, C., Electrosynthesis and Characterization of Viologen Cross Linked Thiophene Copolymer. Electrochim. Acta 2013, 97, 378385.

4. Tang, X.; Schneider, T.; Buttry, D. A., A Vibrational Spectroscopic Study of the Structure of Electroactive Self-Assembled Monolayers of Viologen Derivatives. Langmuir 1994, 10, 2235-2240. 5. Liu, B.; Blaszczyk, A.; Mayor, M.; Wandlowski, T., Redox-Switching in a Viologen-Type Adlayer: An Electrochemical Shell-Isolated Nanoparticle Enhanced Raman Spectroscopy Study on Au(111)-(1×1) Single Crystal Electrodes. ACS Nano 2011, 5, 5662-5672. 